\title{
Sustentabilidade da pecuária leiteira do semiárido brasileiro com base em vulnerabilidade e resiliência socioecológica
}

A pecuária leiteira possui estreita relação com os fatores que conduzem a vulnerabilidade e a resiliência dessa atividade, fatores estes que determinam a sustentabilidade desse sistema socioecológico. Assim, objetivou-se com o presente estudo avaliar a sustentabilidade da pecuária leiteira no semiárido brasileiro com base em vulnerabilidade e resiliência socioecológica. O levantamento de dados foi realizado em 2018 através de questionários para uma amostra de 204 estabelecimentos agropecuários, dividida igualmente entre os municípios paraibanos de Barra de Santana, Boqueirão e Caturité. Considerou-se as variáveis: média do efetivo bovino; o tipo de sistema de produção se intensivo, semi-intensivo ou extensivo; raças mais utilizadas; produção leiteira; forma de comercialização do leite e de aquisição de ração; número de produtores que recebem assistência técnica; área de palma cultivada; área sob ataque e resistentes à Cochonilha-docarmim. Os dados obtidos foram submetidos a uma análise estatística. A vulnerabilidade da pecuária leiteira nos municípios estudados se deve principalmente à falta de assistência técnica aos produtores e a deficiência na utilização de técnicas de manejo visando o controle da Cochonilha-do-carmim, Dactylopius sp e uso de raças com aptidão leiteira. O município de Caturité foi considerado mais resiliente em função da presença de tecnologias de manejo adotadas que resultam no aumento da produtividade e renda dos produtores refletindo na sustentabilidade da atividade. Já Barra de Santana está mais vulnerável devido à baixa produtividade leiteira e à forte presença de intermediários no escoamento da produção comprometendo a sustentabilidade da atividade no município.

Palavras-chave: Municípios; Produtores; Rebanhos.

\section{Sustainability of dairy farming in the Brazilian semi-arid region based on vulnerability and socio-ecological resilience}

\begin{abstract}
Dairy farming has a close relationship with the factors that lead to the vulnerability and resilience of this activity, factors that determine the sustainability of this socio-ecological system. Thus, the objective of this study was to evaluate the sustainability of dairy farming in the Brazilian semi-arid based on vulnerability and socio-ecological resilience. The data collection was carried out in 2018 through questionnaires for a sample of 204 agricultural establishments, divided equally between the Paraíba municipalities of Barra de Santana, Boqueirão and Caturité. Variables were considered: bovine cattle population; the type of intensive, semiintensive or extensive production system; most used breeds; dairy production; form of commercialization of milk and purchase of feed; number of producers receiving technical assistance; cultivated cactos forage area; area under attack and resistance to Carmine Cochineal. The data obtained were subjected to statistical analysis. The vulnerability of dairy farming in the municipalities studied is mainly due to the lack of technical assistance to producers and the deficiency in the use of management techniques aiming at the control of carmine cochineal Dactylopius sp. The municipality of Caturité was considered more resilient due to the presence of management technologies adopted that result in increased productivity and income for producers, reflecting on the sustainability of the activity. Barra de Santana, on the other hand, is more vulnerable due to the low dairy productivity and the strong presence of intermediaries in commercialization of the products, compromising the sustainability of the activity in the municipality.
\end{abstract}

Keywords: Municipalities; Producers; Herds.

Topic: Desenvolvimento, Sustentabilidade e Meio Ambiente

Reviewed anonymously in the process of blind peer.

Sara Camelo Aguiar 10

Universidade Federal de Campina Grande, Brasil

http://lattes.cnpq.br/8644996152479570

http://orcid.org/0000-0002-1560-9981

saracameloag@hotmail.com

Vera Lucia Antunes de Lima (i

Universidade Federal de Campina Grande, Brasil

http://lattes.cnpq.br/5379077061489077

http://orcid.org/0000-0001-7495-6935

antuneslima@gmail.com

Patrícia Ferreira da Silva

Universidade Federal de Campina Grande, Brasil

http://lattes.cnpq.br/8146309314429987

http://orcid.org/0000-0002-4580-2336

patrycyafs@yahoo.com.br
Received: 01/02/2020

Approved: 09/03/2020

\author{
José Dantas Neto \\ Universidade Federal de Campina Grande, Brasil \\ http://lattes.cnpq.br/9137226205129315 \\ http://orcid.org/0000-0003-0798-6717 \\ zedantas1955@gmail.com
}

Maria Sallydelândia Sobral de Farias (it)

Universidade Federal de Campina Grande, Brasi

http://lattes.cnpq.br/6509819298535266

http://orcid.org/0000-0002-3255-2024

sallyfarias@hotmail.com

\section{Referencing this:}

AGUIAR, S. C.; LIMA, V. L. A.; SILVA, P. F.; DANTAS NETO, J. D.; FARIAS, M. S. S.. Sustentabilidade da pecuária leiteira do semiárido brasileiro com base em vulnerabilidade e resiliência socioecológica. Revista Ibero Americana de Ciências Ambientais, v.11, n.2, p.236-248, 2020. DOI: http://doi.org/10.6008/CBPC2179-6858.2020.002.0025 


\section{INTRODUÇÃO}

A sustentabilidade da pecuária leiteira na região semiárida é de essencial relevância para o fortalecimento desta atividade, uma vez que, envolve o aumento de produção e renda, implicando numa melhoria generalizada das condições de vida e de trabalho no espaço agrícola, além de gerar simultaneamente impactos positivos para o meio ambiente (GOMES et al., 2012).

Coutinho et al. (2013) relatam que a região semiárida é caracterizada pela prática de uma pecuária leiteira extensiva. Contudo, essa pecuária extensiva deve preconizar pel sustentabilidade do ambiente em que se desenvolvi, visto que para o consumidor preocupado com o modo que é produzido o alimento, a informação de quão sustentável é a atividade pode ser uma informação decisiva na hora da escolha do produto, e também para o próprio produtor entender os processos e saber dos gargalos e pontos a serem melhorados para tornar a criação desses animais para uma melhor eficiência e com menor impacto sobre o ambiente (NÓBREGA et al., 2011).

A região semiárida apresenta grandes limitações em relação ao crescimento da pecuária leiteira, em especial em decorrência da baixa oferta de alimentos, água e o os custos de produção. No entanto, mesmo com este cenário adverso, a atividade leiteira tem um importante papel na sobrevivência das propriedades agrícolas familiares, tanto no autoconsumo como na geração de renda, o que permite a diversificação da propriedade e a integração com meios mais sustentáveis de produção (SILVA JÚNIOR et al., 2018).

De acordo com Adger et al. (2005) uma das formas de analisar uma determinada atividade quanto as suas limitações e impactos está associada a estudos de vulnerabilidade e da resiliência. A vulnerabilidade pode ser entendida como redução de vulnerabilidade, seja ao moderar sensibilidades, seja no fortalecimento da capacidade adaptativa. Já a resiliência pode ser abordada como construção de resiliência.

Nesse sentido, o que uni vulnerabilidade e resiliência dentro do contexto de sustentabilidade está atrelado a compreensão do funcionamento dos sistemas socioecológicos para tomada de decisão informada visando à redução de riscos socioambientais. E o que as separa é a forma de abordar o problema e as distinções teóricas e metodológicas (LINDOSO, 2017).

Os sistemas socioecológicos ditos resilientes são aqueles que se revelam mais competentes para sair de situações ditas de vulnerabilidades. No caso da pecuária, são os produtores que possuem maior engajamento em associações para compra de ração para os animais, participam de cursos de capacitação, possuem reservas de alimentos produzidos em épocas chuvosas e comercializam seu leite em conjunto com outros produtores. Dada a relevância da temática, objetivou-se com este trabalho avaliar a sustentabilidade da pecuária leiteira no semiárido brasileiro com base em vulnerabilidade e resiliência socioecológica.

\section{METODOLOGIA}

O estudo foi desenvolvido nos municípios de Barra de Santana, Boqueirão e Caturité, pertencentes à microrregião do Cariri Oriental paraibano que se situa na mesorregião da Borborema semiárido do Brasil (Figura 1), entre as coordenadas de 70 e $8^{\circ} 30^{\prime}$ latitude sul e $36^{\circ}$ e $37^{\circ} 30^{\prime}$ de longitude oeste, com altitude 
para níveis de 400 a 600 metros (BRASIL, 2010). O levantamento de dados para o presente trabalho foi realizado em 2018.

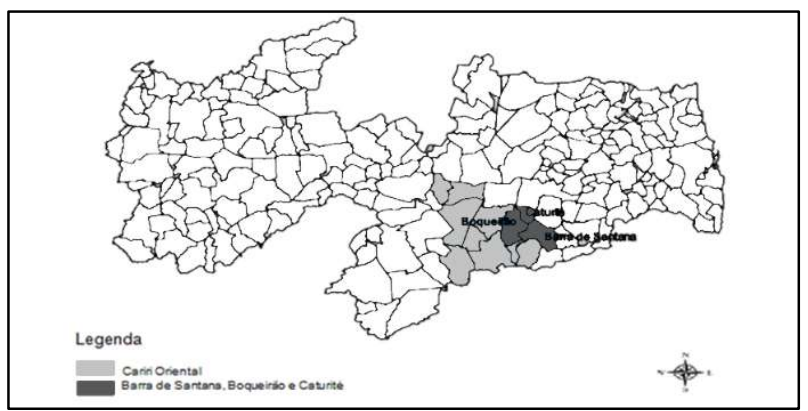

Figura 1: Localização dos municípios de Barra de Santana, Boqueirão e Caturité na microrregião do Cariri Oriental da Paraíba.

Segundo a classificação de Koopen esses municípios possuem o tipo climático Bsh-semiárido quente e estão localizados na área mais seca do estado da Paraíba com os mais baixos índices pluviométricos do estado, as precipitações médias anuais possuem uma média de $500 \mathrm{~mm} \mathrm{ano}^{-1}$ e a estação seca pode atingir onze meses (BRASIL, 2010). A vegetação típica da região é a Caatinga que se distribui em dois tipos: hiper e hipoxerófila. Seus solos são rasos e pedregosos, predominando os Bruno Não Cálcicos e os Litólicos (BRASIL, 2010).

Apesar do pequeno porte desses municípios, Barra de Santana, Boqueirão e Caturité, atualmente em seus territórios existem duas usinas de beneficiamento de leite, a Cooperativa Agropecuária do Cariri (COAPECAL), criada em 1997, no município de Caturité, e Indústria e Comércio de Derivados de Leite Ltda (D'Leite), criada em 2007, no município de Barra de Santana. A presença de estabelecimentos dessa natureza evidencia a importância da produção de leite nos diversos setores econômicos do semiárido a partir da geração de emprego e renda na produção, industrialização e comercialização do leite e seus derivados.

A investigação se deu a partir de um levantamento de campo por meio da aplicação de questionários, de maio a setembro de 2018. Considerando que Barra de Santana, Boqueirão e Caturité somam um total de 1.356 estabelecimentos agropecuários voltados a pecuária bovina leiteira (IBGE, 2006), foi utilizada uma amostra de 204 estabelecimentos, alcançando representatividade de aproximadamente $15 \%$. A amostra foi dividida igualmente entre os municípios, sendo destinados 68 questionários para cada um, conforme o que preconiza os levantamentos por meio de questionários (KINNEAR et al., 1979).

Avaliou-se a sustentabilidade da pecuária leiteira no semiárido com base em vulnerabilidade e resiliência socioecológica a partir da caracterização da atividade bovina leiteira em Barra de Santana, Boqueirão e Caturité, considerando as variáveis: média de efetivo bovino nos municípios estudados determinados com base no número de animais presentes na propriedade; o tipo de sistema de produção se intensivo, semi-intensivo ou extensivo obtido da resposta dos proprietários entrevistados; quais raças são mais utilizadas pelos produtores levando em consideração as que estão em maior presença em cada propriedade no período investigado; a média da produção leiteira em cada propriedade com base no volume de litro por dia; a forma de comercialização do leite produzido se in natura ou processado, se venda direta ao consumidor ou por meio de atravessadores; formas de aquisição de ração se individualmente ou por meio 
de cooperativas ou associações; número de produtores que recebem assistência técnica, seja do governo ou mesmo particular, a média de hectares de palma cultivado em cada propriedade e as médias de hectares de palma atacados e resistentes à Cochonilha-do-carmim.

Os dados encontrados foram submetidos à análise estatística descritiva que tem como objetivo organizar, resumir e descrever os aspectos importantes de um conjunto de características observadas ou comparar tais características entre dois ou mais conjuntos (REIS et al., 2002). Foram utilizados gráficos e tabelas como ferramentas para descrição dos resultados.

O estudo foi conduzido a partir do método cientifico sistêmico proposto por (CHRISTOFOLETTI, 2004), uma vez que propõe uma análise de forma integrada do complexo social, ambiental e econômico, proporcionando, portanto, adequação e abrangência para investigar e compreender a sustentabilidade da pecuária leiteira no semiárido mediante a vulnerabilidade e resiliência socioecológica.

\section{RESULTADOS E DISCUSSÃO}

A média dos efetivos (número de cabeças) por propriedade dos municípios estudados encontra-se na Figura 2.

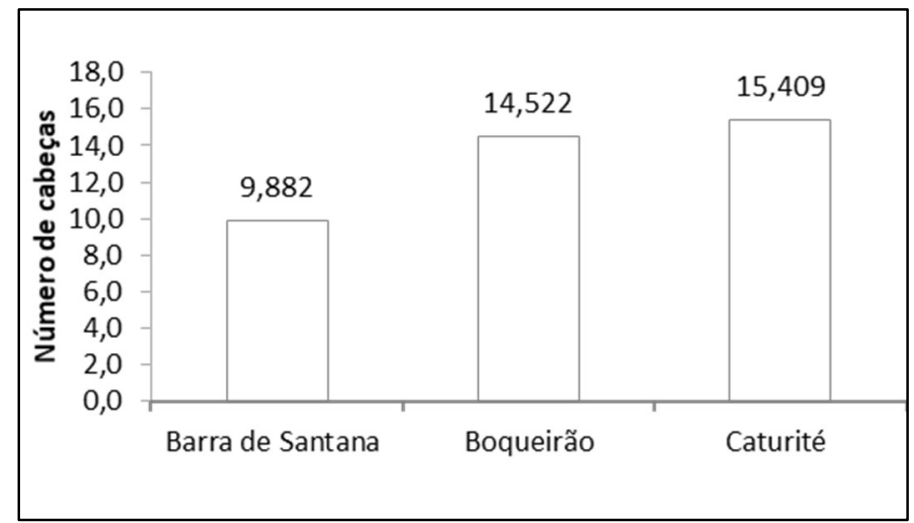

Figura 2: Média dos efetivos (número de cabeças) por propriedade nos Municípios estudados.

Com base na Figura 2 observa-se que o município de Caturité possui a maior média de efetivo bovino por propriedade, embora o Censo Agropecuário de 2017 evidencie que Caturité possui um efetivo total menor entre os três municípios com 5.887 cabeças em 2017. Isso demostra que o efetivo do município de Caturité é mais concentrado entre menos produtores que consequentemente estão mais resilientes nessa variável em função do maior potencial econômico na atividade tendo em vista o maior número de cabeças por estabelecimento, enquanto que o efetivo de Barra de Santana é mais distribuído entre os produtores, o que possivelmente confere ao município maior vulnerabilidade devido a essa distribuição podendo comprometer a sustentabilidade da atividade no município.

A distribuição percentual dos sistemas de produção utilizados nos municípios estudados encontra-se na Figura 3. O sistema semi-intensivo desponta como o mais utilizado, o intensivo possui uma utilização reduzida, embora Boqueirão utilize com expressividade, já o extensivo não é empregado em nenhum dos municípios estudados. 


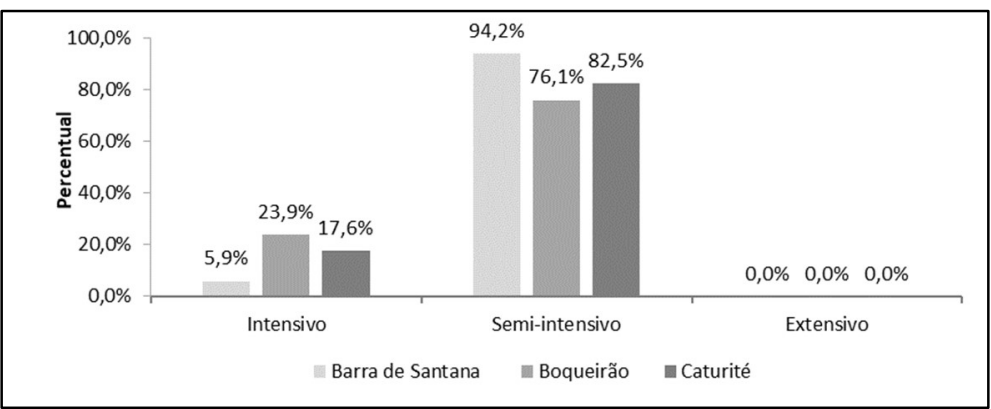

Figura 3: Distribuição percentual dos sistemas de produção nos Municípios estudados

Desse modo, Boqueirão está mais resiliente por utilizar em maior proporção o sistema intensivo que comporta o maior número de animais por hectare e tem elevada capacidade de suporte aos rebanhos (SIMÕES, 2009). Contribuindo para a sustentabilidade da pecuária em função da otimização das áreas das propriedades e do melhor trato dos animais que resultam na eficiência da atividade. Quanto à predominância do sistema de produção semi-intensivo, está se deve principalmente ao confinamento dos rebanhos maior parte do dia em currais, onde recebem alimentação e água. Demonstrando uma possível vulnerabilidade das propriedades em função da dependência da aquisição de ração para os rebanhos.

As composições das rações nessa região basicamente são volumosas, contemplando a palma forrageira considerado o principal alimento fornecido aos rebanhos. Quanto aos concentrados, em geral, são fornecidos torta de algodão, farelos de trigo, milho e soja. Geralmente, após as ordenhas, os rebanhos são levados dos currais para outras áreas, comumente chamadas de cercados, onde pastejam gramíneas quando existentes e, se houver oferta de água, bebem diretamente em açudes, barragens ou reservatórios abastecidos por poços artesianos.

Cabe salientar que a definição do sistema de produção mais adequado para cada região é um dos fatores que podem tornar os produtores de leite mais eficientes e, consequentemente, mais competitivos no mercado (CAMARGO, 1997). Isso também torna a atividade mais sustentável a partir da adoção de mecanismos mais adequados a sua realidade.

É importante citar que para a atividade ser considerada sustentável é necessário produzir com geração de renda, redução de impacto ambiental e manter o homem no campo conforme os preceitos da sustentabilidade, segundo Silva (2015) a Integração Lavoura-Pecuária-Floresta (ILPF) é uma alternativa para esse objetivo, a combinação propositada de árvores, pasto e gado, numa mesma área e ao mesmo tempo, tem se mostrado uma alternativa tecnológica para a produção animal e um forma de enfrentamento à vulnerabilidade.

A distribuição de raças em percentual para cada município estudado, encontra-se na Tabela 1. Notase que as raças Mestiças que "são geralmente derivadas do cruzamento de animais de uma raça pura de origem europeia (E) com animais de uma das raças zebuínas (Z), em vários graus de sangue" (MIRANDA et al., 2009), estão presentes em maiores percentuais em todos os municípios estudados, em segundo, lugar a raça Holandesa, e em terceiro, a combinação entre essas duas raças, Mestiças/Holandesa (Tabela 1). 
Tabela 1: Distribuição percentual das Raças presentes nos Municípios estudados.

\begin{tabular}{|l|l|l|l|}
\hline Raças & Barra de Santana & Boqueirão & Caturité \\
\hline Girolando & $4,5 \%$ & $0,0 \%$ & $6,6 \%$ \\
\hline Holandesa & $12,1 \%$ & $11,9 \%$ & $18,0 \%$ \\
\hline Holandesa/Girolando & $0,0 \%$ & $0,0 \%$ & $1,6 \%$ \\
\hline Meio sangue/ Holandesa & $0,0 \%$ & $2,4 \%$ & $1,6 \%$ \\
\hline Mestiças & $77,3 \%$ & $66,7 \%$ & $62,3 \%$ \\
\hline Mestiças/Girolando & $1,5 \%$ & $0,0 \%$ & $0,0 \%$ \\
\hline Mestiças/ Holandesa & $4,5 \%$ & $19,0 \%$ & $6,6 \%$ \\
\hline Mestiças/Meio sangue & $0,0 \%$ & $0,0 \%$ & $1,6 \%$ \\
\hline Nelore & $0,0 \%$ & $0,0 \%$ & $1,6 \%$ \\
\hline Total & $100,0 \%$ & $100,0 \%$ & $100,0 \%$ \\
\hline
\end{tabular}

Vale destacar que Caturité possui o maior percentual de raça Holandesa, que segundo Carvalho et al. (2003) têm maior aptidão leiteira, já Barra de Santana possui o maior percentual de raças Mestiças que possuem mais resistência, peso e longevidade com maior tempo em produção, porém sua aptidão leiteira é menor (CARVALHO et al., 2003). Portanto, Caturité conta com um rebanho mais resiliente, pois tem maior capacidade produtiva em ternos de produção leiteira gerando consequentemente maior rendimento financeiro, fato este que pode contribuir para a sustentabilidade da atividade no município.

De acordo com Vieira (2012) para que a atividade seja mais resiliente os produtores devem buscar tecnologias como melhoramento genético de seus rebanhos, com a utilização de reprodutores e a inseminação artificial, uma ferramenta biotecnológica que possibilita o melhoramento genético de forma rápida a partir do sêmen de animais de alto padrão genético em propriedades que não podem arcar com os custos para manutenção desses animais.

A média da produção diária de leite por propriedade nos municípios, encontra-se na Figura 4. Notase que o município de Caturité possui a maior média diária de produção. Fato que se devem em especial por Caturité possuir em $18 \%$ de seu rebanho amimais da raça Holandesa que tem maior aptidão para produção de leite, além disso possui $82 \%$ do rebanho em sistema semiextensivo.

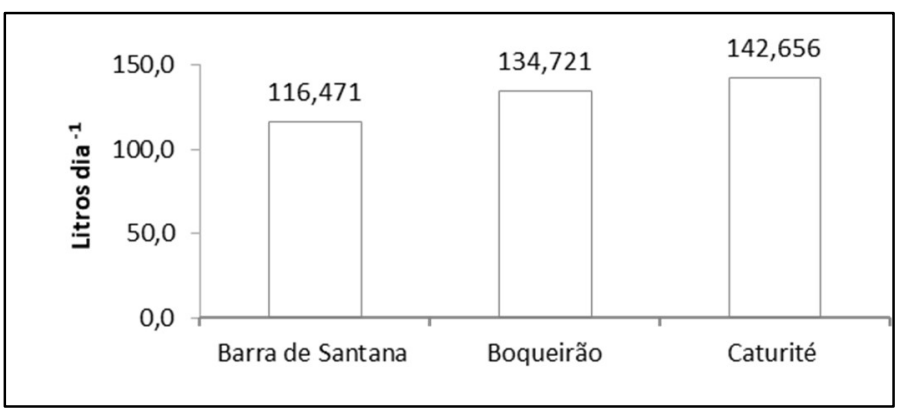

Figura 4: Média de produção litros dia $^{-1}$ de leite por propriedade nos Municípios estudados.

É importante comparar os dados da Figura 4 com o número de vacas ordenhadas em cada município, de acordo com os dados do Censo Agropecuário 2017 (Tabela 2). Segundo a Figura 4, Caturité tem a maior média de produção diária de leite, e de acordo com a Tabela 2, tem o menor número de vacas ordenhadas, portanto, o município possui maior produtividade em relação a Boqueirão e a Barra de Santana, que possuem menores médias de produção diária de leite (Figura 4), e maiores números de vacas ordenhadas (Tabela 2). Essa diferença de produtividade entre os municípios se deve principalmente ao maior percentual da raça Holandesa em Caturité. Nesse sentido, a maior eficiência produtiva do rebanho do município torna sua 
pecuária mais resiliente produzindo mais leite com menos amimais. Essa otimização na produção de leite é reflexo das escolhas dos produtores por raças mais adequadas a produção de leite.

Tabela 2: Número de vacas ordenhadas em Barra de Santana, Boqueirão e Caturité, em 2017.

\begin{tabular}{|l|l|}
\hline Municípios & Vacas ordenhadas \\
\hline Barra de Santana & 4.321 \\
\hline Boqueirão & 2.090 \\
\hline Caturité & 1.688 \\
\hline Total & 8.099 \\
\hline
\end{tabular}

Fonte: IBGE (2017).

Nesse sentido, faz-se necessário que os municípios de Boqueirão e Barra de Santana aprimorem seus rebanhos de forma a superar esta vulnerabilidade, além do melhoramento genético, é fundamental a adequação das raças a atividade escolhida, além disso, deve haver capacitação dos produtores e assistência técnica para alcançar um manejo mais eficiente. Conforme Santos (2009) a resiliência está cada vez mais dependente da capacidade das regiões em inovarem de forma contínua, renovando produtos, competências e conhecimentos para manterem-se na acirrada competição globalizada.

A destinação em percentual da produção de leite se para venda in natura ou processada (queijo), venda direta, intermediários, fábricas e outros encontra-se na Figura 5. Observa-se que Barra de Santana comercializa o leite in natura em maior percentual com destinação a outros produtores e os queijos comercializados por meio de intermediários. Já Boqueirão comercializa seu leite in natura à fábricas e Caturité possui maior percentual de queijos comercializados diretamente ao consumidor (Figura 5).

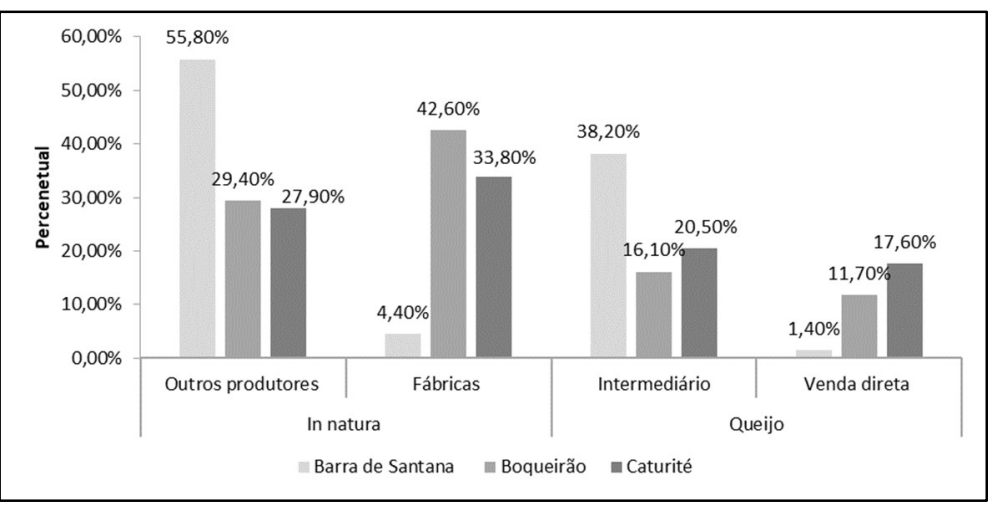

Figura 5: Distribuição percentual da destinação do leite nos Municípios estudados

Barra de Santana utiliza as formas mais vulneráveis para escoar sua produção, seja a venda do leite ou do queijo por meio de intermediário. O que propicia maior vulnerabilidade uma vez que o produtor comercializa seus produtos a preços baixos, impossibilitando que os produtores recebam um pagamento mais justo por seus produtos e alcancem uma renda maior. Já Boqueirão vende o leite expressivamente às fábricas e juntamente com Caturité são os municípios que mais vendem o queijo diretamente ao consumidor final tornando a pecuária leiteira mais resiliente a partir do maior preço dos produtos que se reverte em mais renda para os produtores e suas famílias.

É necessário que os produtores, principalmente de Barra de Santana, busquem canais de venda direta com o consumidor final visando escoar a produção de forma independente ou através de associações e cooperativas. Cabe salientar ainda aque o aumento da resiliência da pecuária leiteira dos municípios pode 
ser favorecido se este vierem a atender a Normativa № 62 do Ministério da Agricultura, Pecuária e Abastecimento que regulamenta a produção, identidade e qualidade do leite (BRASIL, 2011), para melhorar a qualidade e garantir aos consumidores o consumo de produtos lácteos mais seguros e alcançar condições para aumentar o rendimento dos produtores.

A forma de aquisição de ração tipo concentrado encontra-se na Figura 6. Constatou-se que os municípios de Barra de Santana e Caturité realizam suas aquisições expressivamente por meio de intermediários, fato que contribui para aumento do valor do produtor deixando a atividade mais cara para o produtor. Contudo, a maioria dos produtores de Boqueirão compra através de entidades como cooperativas e associações, o que facilita a aquisição de forma a reduzir os custos de produção para o produtor (Figura 6).

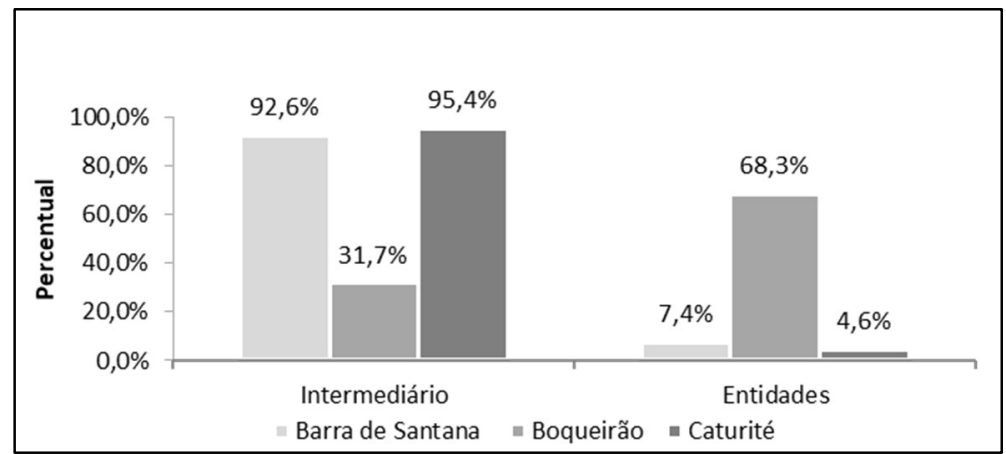

Figura 6: Distribuição percentual das formas de aquisição de concentrado nos Municípios estudados.

A desarticulação dos produtores de Barra de Santana e Caturité demonstra a vulnerabilidade destes municípios para aquisição de concentrado que é o componente de maior custo da ração animal, tornando a pecuária mais frágil e onerosa. Quanto a Boqueirão nota-se maior organização de seus produtores resultando em redução de custos com a alimentação dos rebanhos tornando a pecuária do município mais resiliente e sustentável frente às dificuldades enfrentadas no semiárido.

Entidades como associações e cooperativas são os principais meios para os produtores rurais se engajarem e aprimorarem suas atividades, inclusive para comprarem insumos. Esses mecanismos fortalecem os produtores proporcionando mais representatividade aos interesses da categoria, menor custo na aquisição de produtos e maior poder de comercialização dos seus produtos o que favorece a competitividade aos seus produtos. Segundo Figueiredo et al. (2017) para garantir a resiliência dos sistemas socioecológicos nas diferentes escalas no meio rural são necessárias práticas e alternativas sustentáveis tais como: a integração lavoura pecuária, o melhoramento genético, o engajamento em entidades como associações e cooperativas, fatores estes que servem como instrumentos de gestão e governança, a exemplo das parcerias, organização local e arranjos sócio produtivos.

O percentual de produtores que recebem assistência técnica nos municípios estudados se encontra na Figura7. Observa-se que os produtores dos municípios investigados estão vulneráveis quanto a Assistência Técnica e Extensão Rural (ATER), Barra de Santana possui o maior percentual, ainda assim é um valor considerado baixo, além disso, é o município com menor produtividade. Isto é, além do acesso também é necessário rever a qualidade desse serviço fornecido. 


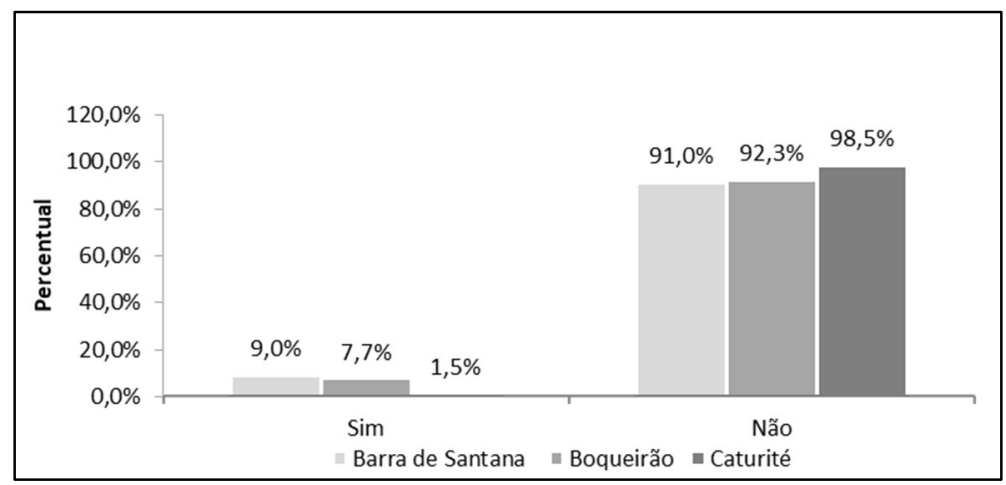

Figura 7: Distribuição percentual dos produtores que recebem ou não Assistência Técnica e Extensão Rural (ATER) nos Municípios estudados.

A falta do ATER pode propiciar a vulnerabilidade da pecuária leiteira pela deficiência de orientações e informações pertinentes ao aprimoramento do manejo da atividade como noções de gestão, adoção de novas tecnologias e informação sobre crédito rural. Cabe salientar que a Assistência Técnica e Extensão Rural (ATER) é de fundamental importância para o aprimoramento da pecuária leiteira, no entanto este serviço tem sido ofertado em quantidade e qualidade inferior os reais necessidade dos produtores.

A ATER consiste em serviços fundamentais para o desenvolvimento rural e da atividade agropecuária, porque é uma ferramenta de difusão do conhecimento de novas tecnologias, originadas da pesquisa, e demais conhecimentos, cabe salientar ainda que os extencionistas devem se familiarizar com a situação problema de cada produtor e não apenas trazer um pacote de soluções para todos da mesma forma (SILVA, 2016).

Além disso, Caporal (2003) defende que a ATER pública precisa tratar os temas da sustentabilidade e da agricultura como "construção social", pautado no entendimento da aprendizagem social. Nesse sentido, a ATER evidencia uma estreita relação com a resiliência que tem a aprendizagem como um de seus pilares para adaptar e transformar situações adversas.

Na Figura 8, encontra-se a área média cultivada com palma, atingida por Cochonilha-do-carmim e cultivada com palma resistente a Cochonilha-do-carmim. O município de Boqueirão possui maior área de palma cultivada por propriedade (Figura $8 \mathrm{~A}$ ), e a maior área com palma resistente à Cochonilha-do-carmim (Figura $8 \mathrm{C}$ ), o que confere ao município mais resiliência. Já Caturité possui a maior área com palma cultivada atingida pela Cochonilha-do-carmim, sendo desta forma considerado mais vulnerável (Figura 8 B).

Boqueirão por possui maior área cultivada de palma resistente a Cochonilha-do-carmim, consequentemente possui maior aporte forrageiro para os rebanhos, conferindo ao município maior resiliência, fato que se justifica em função da palma forrageira ser o principal alimento fornecido aos rebanhos (CARVALHO et al., 2007).

Porém, cabe destacar que apesar de Boqueirão possuir a maior área de palma cultivada (Figura 8 A), conforme estudo de zoneamento agroclimático da cultura para o estado da Paraíba, realizado por Bezerra et al. (2014), é o município de Caturité quem está totalmente dentro da faixa de 'Aptidão plena' para o cultivo da palma forrageira, enquanto que Boqueirão e Barra de Santana tem seus territórios divididos entre as faixas de 'Aptidão plena' e 'Aptidão com restrições'. 
A

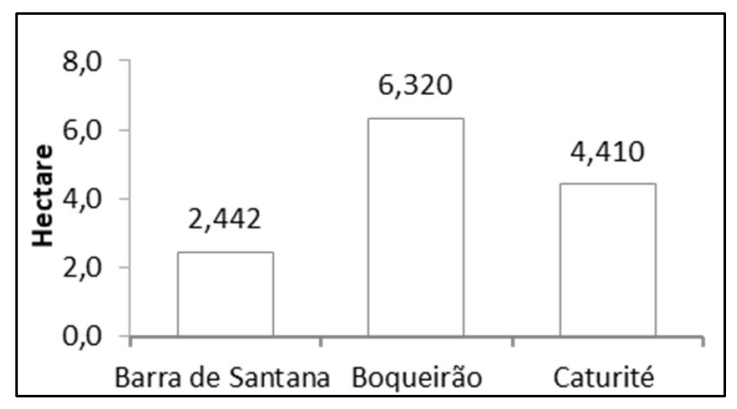

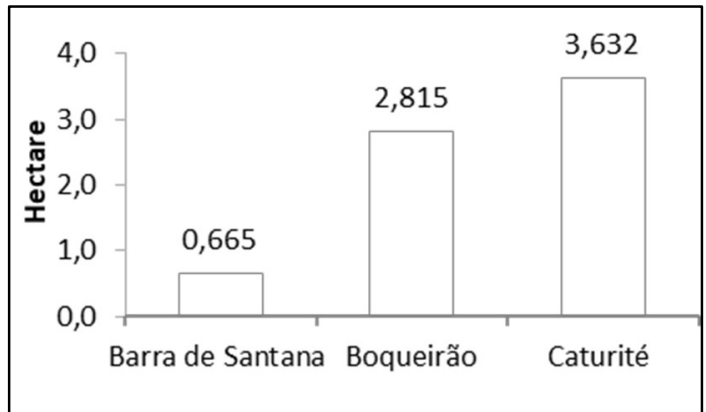

C

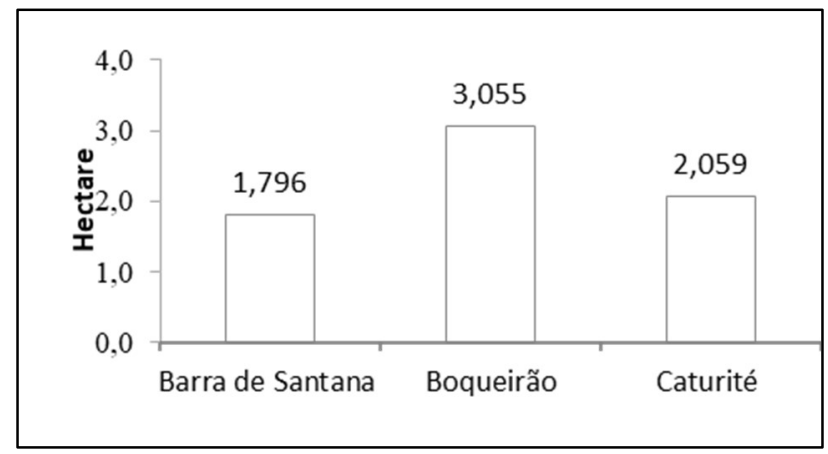

Figura 8: Área média de palma cultivada (A), atingida pela Cochonilha-do-carmim (B) e resistente à Cochonilha-docarmim (C) por propriedade nos Municípios estudados.

Quanto à área atingida pela Cochonilha-do-carmim, Caturité foi severamente atacado pelo inseto mostrando-se mais vulnerável à praga. Já Barra de Santana possui uma área média inferior a 1ha por propriedade afetado pela praga (Figura 8 B), o que se deve, principalmente, ao avanço da Cochonilha-docarmim está acontecendo do sentido oeste para leste (TINÔCO, 2013), desse modo, sua posição geográfica Ihe conferiu mais resiliência em relação aos demais municípios.

Segundo Macêdo (2014), em Caturité a influência da Cochonilha-do-carmim sobre a palma forrageira gigante causou uma desarticulação produtiva local, a praga afetou fortemente o município em meio a um contexto de políticas públicas insuficientes e de descrença cultural dos produtores em relação às variedades de palma resistentes à praga.

Embora trate-se do ataque de um inseto a uma cultura e a vulnerabilidade possua abordagens mais biofísicas, a realidade estudada se enquadra adequadamente nas abordagens mais social sobre vulnerabilidade, pois suas causas principais são econômicas, políticas, sociais e culturais, estas que por sua vez, diminuem a capacidade dos sistemas socioecológicos prevenirem-se ou responderem de modo satisfatório a impactos externos (LINDOSO, 2017).

No entanto, segundo Pinto (2015) as variedades resistentes à Cochonilha-do-carmim estão representando um importante alternativa para continuação da pecuária leiteria nos municípios de Boqueirão e Caturité. Conforme Santos (2009) as crises também podem ser oportunidades para transformação que permite reconstruir a resiliência do sistema.

De acordo com Gonçalves (2017) a resiliência varia entre a competência que um sistema socioeconômico demonstra para se recuperar de um choque ou de uma disrupção, a possibilidade que uma economia manifesta para manter equilíbrio durante uma crise. 
Segundo a Tabela 3, as variedades de palma forrageira resistentes à Cochonilha-do-carmim mais cultivadas nos municípios de Barra de Santana e Boqueirão são Doce (Nopalea cochinillifera) e Orelha de Elefante (Opuntia spp), já em Caturité essa ordem é invertida, cultiva-se mais a Orelha de elefante seguida da Doce.

Tabela 3: Distribuição percentual das variedades de palma resistentes à Cochonilha-do-carmim cultivadas nos Municípios estudados.

\begin{tabular}{|l|l|l|l|}
\hline Cultivares & Barra de Santana & Boqueirão & Caturité \\
\hline Doce & $53,0 \%$ & $47,2 \%$ & $27,7 \%$ \\
\hline Doce/Mão de moça & $1,5 \%$ & $0,0 \%$ & $0,0 \%$ \\
\hline Doce/Mexicana & $0,0 \%$ & $0,0 \%$ & $2,1 \%$ \\
\hline Doce/Miúda & $1,5 \%$ & $0,0 \%$ & $0,0 \%$ \\
\hline Doce/Orelha de elefante & $39,4 \%$ & $11,1 \%$ & $23,4 \%$ \\
\hline Doce/Orelha de elefante/Baiana & $0,0 \%$ & $2,8 \%$ & $0,0 \%$ \\
\hline Doce/Orelha de elefante/Mão de moça & $0,0 \%$ & $2,8 \%$ & $0,0 \%$ \\
\hline Mão de moça & $0,0 \%$ & $0,0 \%$ & $6,4 \%$ \\
\hline Mexicana/Baiana & $0,0 \%$ & $0,0 \%$ & $2,1 \%$ \\
\hline Orelha de elefante & $4,5 \%$ & $33,3 \%$ & $36,2 \%$ \\
\hline Orelha de elefante/Baiana & $0,0 \%$ & $2,1 \%$ \\
\hline Orelha de elefante/Mão de moça & $0,0 \%$ & $2,8 \%$ & $0,0 \%$ \\
\hline Total & $0,0 \%$ & $100,0 \%$ & $100,0 \%$ \\
\hline
\end{tabular}

A variedade Doce apesar de mais exigente em fertilidade de solo é mais nutritiva e palatável para os animais (GALVÃO JÚNIOR et al., 2014), o que atribui mais qualidade de forragem a Barra de Santana e Boqueirão e consequentemente mais desempenho produtivo dos seus rebanhos.

A palma Doce já era uma cultivar conhecida pelos produtores dos municípios pesquisados antes do ataque da Cochonilha-do-carmim, mas sua introdução significativa, bem como da Orelha de Elefante, se deu após o ataque da praga por meio de doações dos postos da então Empresa de Assistência Técnica e Extensão Rural da Paraíba (EMATER), sindicatos de trabalhadores rurais e políticos locais.

A distribuição percentual para realização de combate ou controle da Cochonilha-do-carmim se encontra na Figura 9. Verifica-se que os municípios Boqueirão e Caturité possuem algum tipo de mecanismo para controle da Cochonilha-do-carmim nos palmais, porém, o município de Barra de Santana não utiliza nenhuma estratégia de controle deste inseto (Figura 9).

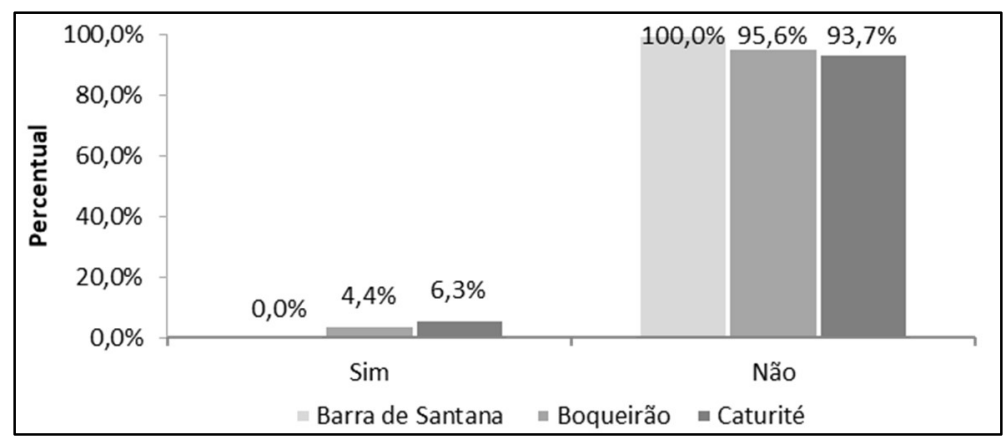

Figura 8: Distribuição percentual da realização ou não de ação de combate e controle à Cochonilha-do-carmim nos Municípios estudados.

Dentre as poucas ações realizadas em Boqueirão e Caturité foram citadas a utilização de queimadas e de agrotóxico. O plantio das cultivares resistentes é uma importante ação de controle da Cochonilha-docarmim, pois o inseto não se alimenta dessas cultivares culminando com sua morte, e também uma prática 
comumente realizada pelos produtores é a retirada da palma nos pontos mais atingidos pela praga, de modo a preservar os pontos menos atingidos, poupando o palmal por mais tempo.

As variedades de palma resistentes à Cochonilha-do-carmim garantem a continuação da pecuária bovina leiteira no semiárido, confirmando que uma das premissas da resiliência socioecológica é a mudança de regime (regime shift), transitando para um novo domínio ou estado de estabilidade (SCHEFFER et al., 2001). Além disso Chiacchio (2008) recomenda que os produtores realizem inspeções semanais nos palmais, erradiquem imediatamente as plantas com suspeita de ataque do inseto e controlem a praga com pulverizações com sabão em pó a $2 \%$ ou detergente neutro a $5 \%$.

É imprescindível o empenho das autoridades e órgão competentes, bem como dos produtores no combate e controle da Cochonilha-do-carmim. Conforme Lindoso (2017) a resiliência dos sistemas socioecológicos também se dá através dos processos de rearranjo estrutural e auto-organização em resposta a perturbações.

\section{CONCLUSÕES}

A vulnerabilidade da pecuária leiteira nos municípios de Barra de Santana, Boqueirão é em decorrência da falta de Assistência Técnica e Extensão Rural (ATER), acesso a tecnologias como melhoramento genético, controle da Cochonilha-do-carmim, uso de raças com aptidão leiteira, tipo de sistema de cultivo adotado e integração lavoura-pecuária.

Caturité foi considerado mais resiliente em função da presença de tecnologias de manejo, como a presenças mais significativas da raça Holandesa e da venda direta de sua produção resultando em maior produtividade e renda para os produtores e suas famílias contribuindo para a sustentabilidade da pecuária leiteira do município.

A sustentabilidade da pecuária leiteira no semiárido brasileiro deve ser conquistada combatendo as vulnerabilidades, em especial do ataque da Cochonilha-do-carmim que atinge boa parte dos cultivos de palma forrageira, além do uso de animais adaptados.

\section{REFERÊNCIAS}

ADGER, W. N.; ARNELL, N. W.; TOMPKINS, E. L.. Successful adaptation to climate change across scales. Global Environmental Change, v.2, n. 5, p.77-86, 2005. DOI: https://doi.org/10.1016/i.gloenvcha.2004.12.005

BEZERRA, B. G.; ARAÚJO, J. S.; PEREIRA D. D.; LAURENTINO, G. Q.; SILVA, L. L.. Zoneamento agroclimático da palma forrageira (Opuntia sp.) para o estado da Paraíba. Revista Brasileira de Engenharia Agrícola e Ambiental, Campina Grande, v.18, n.7, p.747-753, 2014. DOI: http://dx.doi.org/10.1590/S1415-43662014000700013

BRASIL. Instrução Normativa N. 62 de 2011. Dispões sobre o regulamento técnico de produção, identidade e qualidade de leite tipo A. Brasília: DOU, 2011.

BRASIL. Território do Cariri Oriental. Brasília: MDA, 2010.
CAMARGO, A. C.. Os princípios básicos da produção de leite a pasto. In: CURSO SOBRE MANEJO DE PASTAGEM, 2. Anais. Uberaba: PIAR, 1997.

CAPORAL, F. R.. Bases Para Uma Nova Ater Pública. Tese (Doutorado) - Universidade de Córdoba, Madrid, 2003.

CARAVLAHO, L. A.; NOVAES, L. P.; GOMES, A. T.; MIRANDA, J. E. C.; RIBEIRO, A. C. C. L.. Sistema de Produção de Leite. Juiz de Fora: Embrapa Gado de Leite, 2003.

CARVALHO, R. A.; LOPES, E. B.; SILVA, A. C.; LEANDRO, R. S. CAMPOS, V. B.. Controle alternativo da cochonilha do carmim em palma forrageira no cariri paraibano. Brasília: MMA, 2007. 
CHIACCHIO, F. P. B.. Incidência da cochonilha do carmim em palma forrageira. Bahia Agrícola, Salvador, v.8, n.2, p.12-14, 2008.

CHRISTOFOLETTI, A. L. H.. Sistemas dinâmicos: A abordagem da Teoria do Caos e da geometria fractal em Geografia. In: VITTE, A. C.; GUERRA, A. J. T.. Reflexões sobre a Geografia Física no Brasil. Rio de Janeiro: Bertrand Brasil, 2004.

COUTINHO, M. J. F.; CARNEIRO, M. S. C.; EDVAN, R. L.; PINTO, A. P.. A pecuária como atividade estabilizadora no semiárido brasileiro. Veterinária e Zootecnia, v.20, n.3, p.917, 2013.

FIGUEIREDO, R.A.; ALCÂNTARA, L. C. S.; MORAIS, J. P. G. de; SAIS, A. C.; OLIVEIRA, R. E.. Resiliência em sistemas socioecológicos, paisagem rural e agricultura. Ciência, Tecnologia e Ambiente. Araras. v.5, n.1, p.49-57, 2017.

GALVÃO JÚNIOR, J. G. B.; SILVA, J. B. A.; MORAIS, J. H. G.; LIMA, R. N.. Palma forrageira na alimentação de ruminantes: cultivo e utilização. Acta Veterinária Brasílica, Mossoró, v.8, n.2, p.78-85, 2014. DOI:

https://doi.org/10.21708/avb.2014.8.2.3490

GOMES, P. R; MALHEIROS, T. F.. Proposta de análise de indicadores ambientais para apoio na discussão da sustentabilidade. Revista Brasileira de Gestão e Desenvolvimento Regional, Taubaté, v.8, n.2, p.151-169, 2012.

GONÇALVES, C.. Regiões, cidades e comunidades resilientes: novos princípios de desenvolvimento. Revista Brasileira de Gestão Urbana, Curitiba, v.9, n.2, p.371-385, 2017. DOI: http://doi.org/10.1590/2175-3369.009.002.A015

IBGE. Instituto Brasileiro de Geografia e Pesquisa. Censo Agropecuário 2006. Rio de Janeiro: IBGE, 2006.

IBGE. Instituto Brasileiro de Geografia e Pesquisa. Censo Agropecuário 2017. Rio de Janeiro: IBGE, 2017.

LINDOSO, D. P.. Vulnerabilidade e resiliência: potenciais, convergências e limitações na pesquisa interdisciplinar. Ambiente \& Sociedade, São Paulo, v.20, n.4, p.131-148, 2017.

KINNEAR, T. C.; TAYLOR, J. R.. Marketing research: an applied aproach. McGraw-Hill Companies, 1979.

MACÊDO, H. C.. Influência da cochonilha do carmim (Dactylopius opuntiae) sobre o sistema produtivo da palma forrageira (Opuntia fícus indica Mill) em Caturité-PB.

Monografia (Licenciatura Plena em Geografia) - Universidade Estadual da Paraíba, Campina Grande, 2014.
MIRANDA, J. E. C.; FREITAS, A. F.. Raças e tipos de cruzamentos para Produção de leite. Circular Técnica 98. Juiz de Fora: Embrapa, 2009.

NÓBREGA, G. H.; SILVA, E. M. N.; SOUZA, B. B.; MANGUEIRA, J. M.. A produção animal sob a influência do ambiente nas condições do semiárido nordestino. Revista Verde de Agroecologia e Desenvolvimento Sustentável, Mossoró, v.6, n.1, p.67-73, 2011.

PINTO, I. O.. Diagnóstico e revitalização da palma forrageira como alternativa da pecuária no cariri oriental da Paraíba. Dissertação (Mestrado em Desenvolvimento Regional) Universidade Estadual da Paraíba, Campina Grande, 2015.

REIS, E. A.; REIS, I. A.. Análise Descritiva de Dados. Belo Horizonte: UFMG, 2002.

SANTOS, F. T.. Resiliência estratégica para um desenvolvimento regional sustentável. Estudos Regionais. Lisboa, n.20, p.29-40, 2009.

SCHEFFER, M.; CARPENTER, S.; FOLEY, J. A.; FOLKE, C.; WALKER, B.. Catastrophic shifts in ecosystems. Nature, v.413, n.6856, p.591-596, 2001. DOI: http://doi.org/10.1038/35098000

SILVA JÚNIOR, F. A. P.; SALLES, M. G. F.; PINTO, C. M.; PINTO, O. R, O.; RODRIGUES, I. C. S.. A bovinocultura leiteira na agricultura familiar do município de Barreira, CE. Enciclopédia Biosfera, v.16, n.28, p.1-10, 2018. DOI: http://doi.org/10.18677/EnciBio 2018B1

SILVA, R. O. P.. Assistência Técnica e Extensão Rural no Brasil: um pouco de sua história. Análises e Indicadores do Agronegócio, v.11, n.5, 2016.

SILVA. V. P.. Por uma pecuária sustentável. Colombo: Embrapa Florestas, 2015

SIMÕES, A. R. P.; SILVA, R. M.; OLIVEIRA, M. V. M.; CRISTALDO, R. O.; BRITO, M. C. B.. Avaliação econômica de três diferentes sistemas de produção de leite na região do Alto Pantanal Sul-mato-grossense. Agrarian, Dourados, v.2, n.5, p.153-167, 2009.

TINÔCO, L. B. M.. Tecnologia de convivência com a semiaridez. Campina Grande: INSA, 2013.

VIEIRA, R. J.. Biotécnicas aplicadas à reprodução bovina: generalidades. Ciência Animal, Fortaleza, v.22, p.55-65, 2012.

A CBPC - Companhia Brasileira de Produção Científica (CNPJ: 11.221.422/0001-03) detém os direitos materiais desta publicação. Os direitos referem-se à publicação do trabalho em qualquer parte do mundo, incluindo os direitos às renovações, expansões e disseminacões da contribuicão, bem como outros direitos subsidiários. Todos os trabalhos publicados eletronicamente poderão posteriormente ser publicados em coletâneas impressas sob coordenação da Sustenere Publishing da Companhia Brasileira de Produção Científica e seus parceiros autorizados. Os (as) autores (as) preservam os direitos autorais, mas não têm permissão para a publicação da contribuição em outro meio, impresso ou digital, em português ou em tradução. 